\title{
Prática do autocuidado dos graduandos de Enfermagem durante a graduação e na pandemia do SARS-CoV-2
}

\author{
Self-care practice of Nursing undergraduates during graduation and in the SARS-CoV-2 pandemic \\ Práctica de autocuidado de estudiantes de Enfermería durante la graduación y en la pandemia de
}

SARS-CoV-2

Recebido: 28/07/2021 | Revisado: 02/08/2021 | Aceito: 04/08/2021 | Publicado: 09/08/2021

\author{
Michelle Amorim Ferreira \\ ORCID: https://orcid.org/0000-0001-5585-4925 \\ Universidade Veiga de Almeida, Brasil \\ E-mail:maferreira.enfuva@gmail.com \\ Cristiane Maria Amorim Costa \\ ORCID: https://orcid.org/0000-0003-1089-2092 \\ Universidade do Estado do Rio de Janeiro, Brasil \\ E-mail: cmacosta64@gmail.com \\ Milton Domingues da Silva Junior \\ ORCID: https://orcid.org/0000-0003-1163-9005 \\ Universidade Veiga de Almeida, Brasil \\ E-mail: milton.enf.saúde@bol.com.br \\ Paulo Roberto Ferreira Machado \\ ORCID: https://orcid.org/0000-0003-3578-6907 \\ Universidade Veiga de Almeida, Brasil \\ E-mail:paulo.machado@uva.br \\ Raphaela Nunes Alves \\ ORCID: https://orcid.org/0000-0001-6779-1685 \\ Universidade Veiga de Almeida, Brasil \\ E-mail:rvelemem@hotmail.com \\ Wenderson Bruno Herculano da Silva \\ ORCID: https://orcid.org/0000-0001-5288-4264 \\ Universidade Veiga de Almeida, Brasil \\ E-mail:brunowbhs14@gmail.com
}

\begin{abstract}
Resumo
Pesquisa referente a Trabalho de Conclusão de Curso de Graduação em Enfermagem inserida na Linha de Pesquisa Organização e Gestão do Cuidado dos Serviços de Saúde. O Objetivo desde estudo foi identificar as situações que contribuem ou dificultam a prática do autocuidado dos graduandos de Enfermagem de uma universidade privada do Rio de Janeiro durante o período da graduação e na vivência da pandemia do SARS-CoV-2. Foi realizado um estudo descritivo e exploratório, com abordagem qualiquantitativa em uma Instituição Privada de Ensino Superior situada na Zona Norte da Cidade do Rio de Janeiro por meio de entrevista semiestruturada através de formulário online. Os resultados das questões fechadas, perfil sociodemográfico e socioeconômico foram tabulados em percentual através do software Microsoft Excel, 2010e as questões abertas, qualitativas, foram submetidas à Análise de Conteúdo proposta por Bardim. Participaram da pesquisa 116 graduandos de Enfermagem com predominância em adultos jovens do sexo feminino, solteiros, sem filhos, advindos de família com formação nuclear com renda média familiar de 1 a 3 salários mínimos e que se dedicam aos estudos e trabalho em concomitância. Esta pesquisa atingiu seu objetivo expondo as dificuldades enfrentados na prática do autocuidado pelos graduandos de Enfermagem durante a graduação presencial, avaliando como seu pior fator o estresse advindo da necessidade de estudar em concomitância com atividade laboral e na avaliação da prática do autocuidado durante a pandemia com a virtualização das disciplinas, o principal fator estressor que dificulta a prática do autocuidado é a mudança brusca na rotina dos estudantes.
\end{abstract}

Palavras-chave: Autocuidado; Covid-19; Estudantes de Enfermagem; Pandemias; Teoria de Enfermagem.

\section{Abstrat}

Research on The Completion Of Nursing Undergraduate Course inserted in the Line of Research Organization and Management of Health Services Care. The objective since the study was to identify the situations that contribute or hinder the practice of self-care of nursing undergraduates of a private university in Rio de Janeiro during the undergraduate period and in the experience of the SARS-CoV-2 pandemic. A descriptive and exploratory study was carried out, with a qualiquantitative approach in a Private Institution of Higher Education located in the North Zone of the City of Rio de Janeiro through semi-structured interviews through an online form. The results of closed questions, 
sociodemographic and socioeconomic profile were tabulated in percentage through microsoft excel software, 2010 and the open, qualitative questions were submitted to content analysis proposed by Bardim. The study included 116 nursing undergraduates with predominance in young adults, single, without children, from a family with nuclear education with an average family income of 1 to 3 minimum wages and who are dedicated to studies and work in concomitance. This research reached its objective by exposing the difficulties faced in the practice of self-care by nursing undergraduates during face-to-face graduation, evaluating how their worst factor is stress from the need to study in concomitance with work activity and in the evaluation of the practice of self-care during the pandemic with the virtualization of disciplines, the main stressing factor that hinders the practice of self-care is the sudden change in the routine of students.

Keywords: Self Care; Coronavirus Infections; Students, Nursing; Pandemics; Nursing Theory.

\section{Resumen}

Investigación sobre lafinalizacióndel curso de pregradoenenfermería insertado enla Línea de Investigaciónorganización y gestión de losservicios de saludasistencial. El objetivo desde elestudiofue identificar lassituaciones que contribuyen o dificultanlaprácticadel autocuidado de losestudiantes de enfermería de una universidad privada de Río de Janeiro durante el período de graduación y enla experiencia de la pandemia de SARSCoV-2. Se realizóunestudiodescriptivo y exploratorio, conabordajecuantitativoen una Institución Privada de Educación Superior ubicadaenla Zona Norte de laCiudad de Río de Janeiro, a través de entrevistas semiestructuradas a través de unformularioen línea. Los resultados de las preguntas cerradas, sociodemográficas y de perfil socioeconómico fueron tabulados enporcentaje a través del software Microsoft Excel, 2010 y las preguntas abiertas y cualitativasfueron sometidas al análisis de contenidopropuesto por Bardim. El estudioincluyó a 116 estudiantes de graduaciónenenfermeríaconpredominioen adultos jóvenes, solteros, sinhijos, de una familiaconeducación nuclear conuningreso familiar promedio de 1 a 3 salarios mínimos y que se dedican a estudios y trabajanenconcomitancia. Esta investigaciónalcanzó su objetivo al exponerlasdificultades enfrentadas enlaprácticadel autocuidado por parte de losestudiantes de enfermería durante lagraduación presencial, evaluandocómo su peorfactor es elestrés por lanecesidad de estudiarenconcomitanciaconlaactividad laboral y enlaevaluación de laprácticadel autocuidado durante la pandemia conlavirtualización de disciplinas, el principal factorestresante que dificulta laprácticadel autocuidado es el cambio repentino en la rutina de losestudiantes.

Palabras clave: Autocuidado; Infecciones por Coronavirus; Estudiantes de Enfermería; Pandemias; Teoría de Enfermería.

\section{Introdução}

Dados recentes dos conselhos regionais de enfermagem (CORENs), março de 2021, mostram que no brasil há 2.447.562 profissionais de enfermagem com registros ativos, distribuídos em 603.676 enfermeiros, 1.413 .425 técnicos de enfermagem, 430.154 auxiliares de enfermagem e 307 obstetrizes. Deste quantitativo de enfermeiros, 58.891 mil profissionais atuam no estado do rio de janeiro. No país em 2018, havia mais de 819 cursos de nível superior na modalidade presencial registrados, porém este quantitativo representa um percentual muito baixo do total de profissionais referentes à equipe de enfermagem. Vale ressaltar que 57,2\% destes profissionais têm sua formação a partir da iniciativa privada (Conselho Federal de Enfermagem, enfermagem em números, 2021; Da Silva \& Machado, 2020).

O crescente número de escolas de enfermagem, sem contar com o ensino na modalidade de ensino a distância (EAD), preocupam quanto a qualidade dos novos profissionais enfermeiros inseridos no mercado de trabalho, já que o excessivo número delas dificulta o acompanhamento de forma efetiva do ministério da educação e cultura (MEC) e dos conselhos regionais de enfermagem (COREN), seguindo as diretrizes emitidas pelo conselho federal de enfermagem (COFEN). Os dados das inscrições ativas apontam a desigualdade do número de profissionais enfermeiros atuantes em relação aos outros profissionais da equipe de enfermagem, demonstrando possível fragilidade da assistência prestada visto que, cabe ao profissional enfermeiro a supervisão e capacitação por meio de educação continuada da equipe de enfermagem (Da Silva \& Machado, 2020).

Durante a prática laboral o profissional de enfermagem está exposto a riscos ocupacionais, independentemente das suas ações, já que sua profissão é considerada de risco. Dentre as categorias de riscos, o contato com materiais biológicos como sangue, urina, fezes entre outros fluídos corporais possuem alta gravidade, levando em consideração que, tais materiais 
podem conter microrganismos patogênicos que vão adoecer e afastar o profissional de enfermagem de suas atividades (Gómez, Ferreira, Blanco, Osorio \& Torres, 2020). Dos patógenos causadores de infecções ocupacionais podemos citar os vírus, como: da hepatite b (HBV), o da hepatite c (HCV), da imunodeficiência humana (HIV) e o mais citado atualmente, Coronavírus 2 (sars-cov-2) (conselho federal de enfermagem, parecer de câmara técnica n 014/2020/ctas/cofen, 2020; nogueira,2021).

Deste modo, é de extrema importância a abordagem da prática do autocuidado durante a graduação deste estudante, incentivando-o as boas práticas de autocuidado, que vão mitigar os seus riscos e favorecer qualidade de vida (Gómez et al., 2020).

Essa relevância aumentou quando, em dezembro de 2019, o mundo foi surpreendido pelo comunicado da organização mundial de saúde (OMS) do surgimento de uma mutação do vírus conhecido como Coronavírus, denominado Coronavírus 2 , causador da doença Coronavirus disease 2019 (Covid-19), uma zoonose, na Cidade de Wuham, china. O novo Coronavírus apresentou-se com alta taxa de transmissibilidade e característica de desenvolver casos de síndrome respiratória aguda grave. Sua transmissão ocorre predominantemente através de gotículas disseminadas de secreções orofaríngeas de um indivíduo infectado para outro não infectado (transmissão direta) ou por contato de superfícies e objetos contaminados (transmissão indireta), sendo seu maior veículo as mãos (Aquino et al.,2020).

A OMS declarou estado de emergência em Saúde Pública em janeiro de 2020 e em março de 2020 declarou o novo Coronavírus como pandemia, ocasionando grande impacto econômico, sanitário e social em praticamente todos os países do mundo. Por ser tratar de uma nova doença, sua terapêutica não era específica, sua alta taxa de transmissibilidade e a inexistência de vacina a OMS viu a necessidade de recomendar aos governos medidas de intervenções não farmacológicas (INF) tais como: lavagens das mãos, uso de máscaras, desinfecção rotineira de ambientes e restrição ou proibição de locais que pudessem gerar aglomerações de pessoas (Aquino et al.,2020).

No Brasil, o Ministério da Saúde (MS) seguindo as orientações da OMS, adotou em março de 2020 medidas de isolamento social com o uso obrigatório de máscaras caseiras, orientações quanto ao uso etiqueta respiratória, fechamento de comércios e instituições de ensino do nível pré-escolar ao universitário, proibição de grandes eventos, viagens e diminuição do fluxo de transporte público, permitindo o funcionamento somente dos serviços considerados essenciais, diminuindo assim, o quantitativo de pessoas nas ruas na tentativa de impedir a alta transmissibilidade da doença no país (Malta et al., 2020). Em março 2021, 12.573 .615 mil casos confirmados com 313.866 mil vidas ceifadas no brasil, sendo destas, 649 trabalhadores da área de enfermagem entre técnicos e auxiliares, enfermeiros e obstetrizes (Conselho Regional de Enfermagem, um ano de dor e luta na Enfermagem,2020).

As mudanças no estilo de vida exigidas diante de uma pandemia atingiram diretamente os estudantes de Enfermagem, já que sua rotina diária foi alterada drasticamente com o anúncio da paralisação das aulas, virtualização das disciplinas do curso e suspensão dos estágios supervisionados. Tendo em vista que as mudanças de rotina advindas de uma pandemia são inéditas para essa geração de estudantes e este ser influenciado pelo ambiente a que estão inseridos, há probabilidade desses indivíduos diminuírem a prática do autocuidado e adoecerem ou perderem o foco necessário para o seu desenvolvimento acadêmico. Igualmente Almeida, Carrer, Souza \& Pillon (2018), sinalizam que fatores estressores aos quais os estudantes de Enfermagem não estão preparados para lidar, podem gerar situações de vulnerabilidade na saúde mental afetando o seu bemestar e podendo ocasionar baixo desempenho acadêmico.

É importante destacar que os longos períodos de aulas, horas reservadas para os estudos fora da sala de aula, demandas da rotina do lar, obrigações advindas do vínculo empregatício, tempo dedicado a família juntamente com as mudanças radicais no cotidiano da prática de estudos em Home Office devido a pandemia com a virtualização das disciplinas 
mediante as medidas de distanciamento social determinadas pela Prefeitura da Cidade do Rio de Janeiro, podendo assim, gerar ansiedade e modificar a prática do autocuidado prejudicando a saúde dos estudantes(Almeida et al., 2018).

Diante dos fatos apresentados e o agravante de estarmos em meio a uma pandemia, faz-se necessário a análise da situação atual do país diante ao enfrentamento a pandemia do novo Coronavírus para se atingir o objeto de estudo que é a prática do autocuidado dos graduandos de Enfermagem durante a graduação e na pandemia da síndrome respiratória aguda grave 2 (SARS-CoV-2).

A Teoria do Autocuidado de Dorothea Elizabeth Orem define, autocuidado como toda ação predeterminada que tem como finalidade garantir a manutenção da vida, envolvendo o crescimento, desenvolvimento e manutenção da integridade do indivíduo, que podem estar relacionados a sua ação direta ou a ação de outrem a seu favor. Existem três tipos de requisitos para avaliação do autocuidado e estes contemplam: requisitos universais ligados às atividades de vida diária do sujeito, requisitos de desenvolvimento e requisitos de desvio de saúde. Deste modo, é de extrema importância o direcionamento dado por meio dos metaparadigmas de uma Teoria de Enfermagem, conjunto de quatro conceitos inter-relacionados sendo eles: pessoa, ambiente, saúde e Enfermagem, para o desenvolvimento do estudo aventado para a promoção e manutenção da saúde do estudante (Mcewen \& Wills, p.133-161, 2016).

A concepção da Teoria de Enfermagem vem para explicar fenômenos e a partir desses prever resultados. Saber avaliar uma situação ampla com suas inter-relações é fundamental na prática de Enfermagem, visto que o ambiente, o sujeito e a saúde avaliadas em conjunto possibilitam avaliar a realidade e a necessidade do cuidado direcionando as ações de Enfermagem. Em 2020, o estudante de Enfermagem foi submetido a várias mudanças do seu cotidiano devido a pandemia, deste modo, avaliar o conjunto de práticas de autocuidado ou a falta delas, possibilitará realizar uma projeção de que tipos de cuidados esses estudantes necessitarão a longo prazo e facilitando talvez a avaliação do perfil de profissional que chegará ao mercado de trabalho mediante as experiências vividas na graduação perante uma pandemia(Vitor, Lopes \& Araújo, 2010; Felisberto, Giovannini, Diógenes, Carlos \& Lins, 2020).

Diante do exposto, surgiu o seguinte questionamento: quais mudanças ocorrem na prática do autocuidado dos estudantes de Enfermagem ao longo da graduação e com o advento da pandemia?

Não foi encontrado na literatura estudo semelhante, que abordasse a temática do autocuidado do graduando de enfermagem em suas múltiplas variáveis com dados socioeconômicos e sociodemográficos comparando com a vivência de uma pandemia, sendo sua publicação inédita.

Evidenciando-se a relevância dessa investigação pelo fato de se desconhecer os efeitos da vivência de uma pandemia em um estudante de enfermagem e o que estes podem refletir na nova geração de profissionais que vão prestar assistência à saúde da população. Em tempo, este estudo em concomitância com outros que possam vir a emergir, pode auxiliar estudantes, professores e instituições de ensino a identificar possíveis agravos à saúde devido ao déficit de autocuidado dos estudantes de enfermagem durante a graduação e na vivência de uma pandemia que possam levar ao abandono da graduação e/ou se tornarem impeditivos para o ingresso no mercado de trabalho, na tentativa de contorná-los, diminuindo seus efeitos nocivos na vivência desses estudantes.

Assim, objetivou-se identificar as situações que contribuem ou dificultam a prática do autocuidado dos graduandos de enfermagem de uma universidade privada do rio de janeiro durante o período da graduação e na vivência da pandemia do SARS-Cov-2. 


\section{Metodologia}

Trata-se de um estudo descritivo e exploratório, com abordagem qualiquantitativa. O tipo de pesquisa descritiva envolve grande número de variáveis a fim de descrever fenômenos e a exploratória é realizada através de instrumentos que tem por objetivo descrever comportamentos sociais. Tanto a abordagem quantitativa quanto a abordagem qualitativa têm por premissa avaliar o ponto de vista dos sujeitos da pesquisa, portanto a análise quantitativa é realizada através da interpretação de símbolos numéricos enquanto a análise qualitativa é realizada a partir da observação, da interação participativa e da interpretação das colocações dos indivíduos participantes da pesquisa (Knechtel, 2014).

A pesquisa foi realizada em uma universidade privada da Cidade do Rio de Janeiro, no bairro da Tijuca, ocorrendo entre fevereiro e março de 2021. A ferramenta de coleta de dados aplicada foi um formulário online pela plataforma do Google Forms, respeitando as medidas de distanciamento social determinadas pela Prefeitura da Cidade do Rio de Janeiro. A referida universidade possui em média 700 graduandos de Enfermagem devidamente inscritos, sendo definida como amostra do estudo 116 participantes entre o $4^{\circ}$ e $10^{\circ}$ período da graduação. Graduandos do $1^{\circ}$ ao $3^{\circ}$ período não foram sujeitos da pesquisa por não terem vivenciado de forma presencial a rotina da instituição.

A aplicação do formulário foi feita através de envio em redes sociais e WhatsApp.

O formulário continha questões referentes ao perfil socioeconômico e demográfico dos participantes e questões fechadas e abertas sobre autocuidado, apoiadas na Teoria do Autocuidado de Dorothea Elizabeth Orem com hipóteses de interesse da pesquisa e que ao mesmo tempo, oferecem amplo campo para novas questões, que surgiram à medida do recebimento das respostas dos participantes. Seguindo assim, de forma espontânea a sua linha de pensamento e de suas experiências (Barboza, Fassarella \& Souza,2020).

Dos critérios de inclusão para a pesquisa: graduandos devidamente matriculados a partir do quarto período no momento da participação da pesquisa e maiores de 18 anos. Dos critérios de exclusão para a pesquisa: foram excluídos graduandos de enfermagem que não se sentiram em condições físicas e emocionais de responder ao questionário, ou impossibilitados por dificuldades de acesso ao formulário.

Todos os requisitos éticos e legais propostos pela Resolução 466/12 do Conselho Nacional de Saúde (CNS) foram respeitados. Sendo assim, para a realização da pesquisa foi solicitado a assinatura do Termo de Anuência Institucional do PróReitor da instituição de ensino superior, e então o projeto foi encaminhado para avaliação do Comitê de Ética em Pesquisa (CEP) com aprovação sob Parecer Consubstanciado No 4.515.919 e CAAE 42597121.1.0000.5291 em 29 de janeiro de 2021.

A pesquisa caracteriza-se como qualitativa, descritiva e exploratória, quanto ao objetivo de levantamento em relação ao método, e qualitativa quanto ao tratamento e análise dos dados que foram coletados por meio de formulário online no período de fevereiro e março de 2021.

Os resultados das questões fechadas, perfil sociodemográfico e socioeconômico foram tabulados em percentual através do software Microsoft Excel, 2010.

As questões abertas foram tratadas através da Análise de Conteúdo propostas por Bardin, onde utilizou-se a técnica de codificação dos conteúdos das respostas dos participantes, analisando as categorias de análise dos textos através de palavras, frases e/ou conceitos similares e mais frequentes nas respostas obtidas pelo instrumento de coleta de dados, onde foi realizada a organização, codificação, categorização dos dados coletados, contextualizando as respostas analisadas com a interpretação dos seus resultados(Bardin, 2016). 


\section{Resultados e Discussão}

Os participantes do estudo foram 116 graduandos de Enfermagem de uma Universidade privado da Cidade do Rio de Janeiro. Estes foram identificados por uma sequência das iniciais Grad. de graduandos, seguido por algarismos indo-arábicos de 1 a 116, garantindo assim, seu anonimato.

Participaram da pesquisa estudantes entre o $4^{\circ}$ e $10^{\circ}$ período da graduação em Enfermagem compreendidos em: $4^{\circ}$ período $n=1(0,9 \%) ; 5^{\circ}$ período $n=9(7,8 \%) ; 6^{\circ}$ período $n=13(11,2 \%) ; 7^{\circ}$ período $n=15(12,9 \%) ; 8^{\circ}$ período $n=16(13,68 \%) ; 9^{\circ}$ período $\mathrm{n}=51(44 \%)$ e $10^{\circ}$ período $\mathrm{n}=11(9,5 \%)$.

A seguir, o quadro 1 apresenta os dados socioeconômicos e sociodemográficos dos graduandos de Enfermagem. Sendo estes, fundamentais para a melhor compreensão das práticas de autocuidados mediante as suas múltiplas variáveis.

Quadro 1 - Características socioeconômicas e sociodemográficas da amostra - Rio de Janeiro, Brasil, 2021.

\begin{tabular}{|c|c|}
\hline Variáveis & Total amostra $\mathrm{N}=116(100 \%)$ \\
\hline 1) Sexo (biológico) & Feminino $n=100(86,2 \%) \rightarrow$ Masculino $n=16(13,8 \%)$ \\
\hline Gênero (como se identifica) & $\begin{array}{l}\text { Feminino } \mathrm{n}=99(85,3 \%) \rightarrow \text { Masculino } \mathrm{n}=16(13,8 \%) \rightarrow \\
\text { Não declarado } \mathrm{n}=1(0,9 \%)\end{array}$ \\
\hline $\begin{array}{l}\text { Orientação sexual } \\
\text { (como se relaciona afetivamente) }\end{array}$ & $\begin{array}{l}\text { Heterossexual } n=101(87,6 \%) \rightarrow \text { Homossexual } n=11(9,5 \%) \rightarrow \text { Bissexual } n=4 \\
(3,4 \%)\end{array}$ \\
\hline 2) Idade & $\begin{array}{l}18 \text { a } 19 \text { anos } n=1(0,9 \%) \rightarrow 20 \text { a } 29 \text { anos } n=83(73,4 \%) \rightarrow 30 \text { a } 39 \text { anos } n=22 \\
(17,1 \%) \rightarrow 40 \text { a } 49 \text { anos } n=9(7,7 \%) \rightarrow 50 \text { a } 59 \text { anos } n=1(0,9 \%)\end{array}$ \\
\hline 3) Raça/Cor (autodeclarada) & $\begin{array}{l}\text { Branca } n=52(44,8 \%) \rightarrow \text { Preta } n=14(12,1 \%) \rightarrow \text { Parda } n=46 \\
(39,7 \%) \rightarrow \text { Asiática } n=2(1,7 \%) \rightarrow \text { Amarela } n=1(0,9 \%) \rightarrow \text { Indígena } n=1(0,9 \%)\end{array}$ \\
\hline 4) Religião atual & $\begin{array}{l}\text { Católico } \mathrm{n}=26(22,4 \%) \rightarrow \text { Evangélico } \mathrm{n}=32(27,6 \%) \rightarrow \text { Espírita } \mathrm{n}=14(12,1 \%) \\
\rightarrow \text { Candomblé } \mathrm{n}=6(5,2 \%) \rightarrow \text { Umbanda } \mathrm{n}=6(5,2 \%) \rightarrow \text { Nenhuma religião } \mathrm{n}=32 \\
(27,6 \%)\end{array}$ \\
\hline Praticante & $\operatorname{Sim} n=55(47,4 \%) \rightarrow$ Não $n=61(52,6 \%)$ \\
\hline 5) Estado civil & $\begin{array}{l}\text { Solteiro (a) } n=89(76,7 \%) \rightarrow \text { Casado (a)/União estável } n=23(19,8 \%) \rightarrow \\
\text { Divorciado (a) } n=4(3,4 \%)\end{array}$ \\
\hline 6) Com quem reside & $\begin{array}{l}\text { Núcleo familiar } n=91(78,4 \%) \rightarrow \text { Família ampliada } n=10(8,6 \%) \rightarrow \text { Amigos } n=6 \\
(5,2 \%) \rightarrow \text { Sozinho (a) } n=9(7,8 \%)\end{array}$ \\
\hline 7) Número de fillhos & Nenhum $n=92(79,3 \%) \rightarrow$ Um $n=14(12,1 \%) \rightarrow$ Dois ou mais $n=10(8,6 \%)$ \\
\hline 8) Trabalha & Sim n=69 $(59,5 \%) \rightarrow$ Não $n=47(40,5 \%)$ \\
\hline Turno & Diurno $n=59(92,4 \%) \rightarrow$ Noturno Não $n=10(8,6 \%)$ \\
\hline 9) local/área onde reside & $\begin{array}{l}\text { Zona Sul } n=10(8,6 \%) \rightarrow \text { Zona Central } n=5(4,3 \%) \rightarrow \text { Zona Norte } n=65(56 \%) \\
\rightarrow \text { Zona Oeste } n=16(13,8 \%) \rightarrow \text { Zona Leste } n=1(0,9 \%) \rightarrow \text { outro Munícipio } n=19 \\
(16,4 \%)\end{array}$ \\
\hline 10) Renda familiar & $\begin{array}{l}\text { Até } 1 \text { salário mínimo } n=6(5,2 \%) \rightarrow \text { De } 1 \text { a } 3 \text { salários mínimos } n=55(47,4 \%) \rightarrow \\
\text { De } 3 \text { a } 5 \text { salários mínimos } n=31(26,7 \%) \rightarrow \text { De } 5 \text { a } 7 \text { salários mínimos } n=13 \\
(11,2 \%) \rightarrow \text { Acima de } 7 \text { salários mínimos } n=11(9,5 \%)\end{array}$ \\
\hline
\end{tabular}

Fonte: Autores (2021). 
Na caracterização sociodemográfica e socioeconômica, pode-se constatar que o sexo feminino tem maior prevalência no curso de graduação em Enfermagem com 86,2\% da amostra, evidenciando a predominância das mulheres em cursos de nível superior (Conselho Federal de Enfermagem, Enfermagem em números, 2021). No mesmo bloco de perguntas quando questionados sobre gênero a amostra não obteve mudança significativa em relação ao sexo biológico em comparação com a identidade de gênero, porém na variável orientação sexual, somando os que se declararam homossexuais e bissexuais, houve uma mudança com um n=15 (12,9\%) participantes. Apesar desse percentual ser pequeno em relação aos que se declararam cisgêneros (CIS), verifica-se a o ingresso dessa população ao nível superior o que pode vir a contribuir para a diminuição do preconceito, melhora no atendimento dos serviços de saúde, diminuição da vulnerabilidade e melhora na adesão ao tratamento da população de Lésbicas, Gays, Bissexuais e Transgênero (LGBT) (Costa et al.,2020).

A faixa etária predominante do curso de Enfermagem foi entre 20 a 29 anos com um n=83 (73,4\%), adultos jovens, evidenciando a predominância dessa faixa etária em cursos de nível superior (Coelho, Carvalho \& Porcino, 2019).

Considerando a classificação do Instituto Brasileiro de Geografia e Estatística (IBGE), Características étnico-raciais da população, (2013) que unifica pardos e pretos de uma amostra, a população preta tem a maior participação no curso de Enfermagem da referida universidade com um $n=60$, totalizando $51,8 \%$ da amostra. Este percentual pode ser reflexo das políticas públicas que visam a expansão, democratização e universalização do ensino superior como é o caso do Programa Universidade para Todos (PROUNI) que auxilia no ingresso de grupos mais vulneráveis da sociedade em instituições de nível superior particulares através de bolsas de estudos (Bublitz, Guido, Kirchhof, Neves \& Lopes, 2015).

Quanto a religiosidade, a maior parte dos estudantes, $\mathrm{n}=84(72,5 \%)$ possuem alguma religião, destes um $\mathrm{n}=55$ $(47,4 \%)$ afirmam serem praticantes. Os que se declaram não praticantes, $n=61(52,6 \%)$, não são maioria na amostra, pois neles estão incluídos os que declararam não possuir nenhuma religião, $n=32$ (27,6\%), reduzindo os não praticantes em um n=29 (25\%). Possuir e praticar uma religião remete a sentimentos positivos e esperança com enfrentamento dos problemas que surgem durante a vida, melhorando a qualidade de vida do indivíduo (Nunes, Leal, Marques \& Mendonça, 2017).

Os solteiros foram maioria na amostra com n=89 $(76,7 \%)$. Declaram fazerem parte de uma família com base nuclear n=91 (78,4\%). Igualmente ocorreu quando analisado o número de filhos com n=92 $(79,3 \%)$ para os que declararam não terem filhos, demostrando que o perfil do graduando de Enfermagem é predominante de adultos jovens, solteiros e sem filhos (Coelho et al., 2019). Os estudantes que declaram serem casados e/ou vivem em regime de união estável e declaram possuírem filhos estão em menor número, porém está parcela de estudantes possui mais um fator estressor no seu dia a dia, pois precisam conseguir dedicar tempo e cuidados a eles. A família tem papel fundamental, ela constitui a principal categoria da rede de apoio ao estudante e corroboram para o seu fortalecimento psíquico e equilíbrio emocional (Almeida, Carrer, Souza \& Pillon, 2018).

Os estudantes que se dedicam aos estudos e trabalho em concomitância são maioria na amostra n=69 (59,5\%). Destes $\mathrm{n}=59(92,4 \%)$, trabalham no período diurno e $\mathrm{n}=10(8,6 \%)$ no período noturno, o que demonstra dupla jornada diária entre trabalho e estudos. A graduação de Enfermagem tem boa parcela dos seus estudantes trabalhadores de nível técnico em busca de melhores condições de salários (Fontana \& Brigo, 2012). Conciliar estudos, carga horária de trabalho e as múltiplas tarefas do dia a dia em conjunto com as relações entre familiares e amigos pode induzir o sentimento de frustação no estudante tendo em vista que, suas escalas muitas das vezes precisam ser adaptadas e acabam por coincidirem com fins de semana e feriados (Maier \& Mattos, 2016).

Quanto ao local que reside, um total de $\mathrm{n}=65$ (56\%) declaram residir na Zona Norte da Cidade do Rio de Janeiro, mesma área da Instituição de Ensino Superior participante do estudo, ressaltando que a Zona Norte possui 80 bairros com 203, $47 \mathrm{~km}^{2}$ de extensão (Instituto Brasileiro de geografia e Estatística, Censo Demográfico, 2010). Contudo, todas as outras áreas foram citadas, inclusive outros Munícipios com um total de $n=19$ (16,4\%). Vale ressaltar que, a distância do local de residência 
para a instituição de ensino também colabora para a diminuição de tempo livre do estudante levando-o ao cansaço extremo, sentimento de frustação e quadros de ansiedade (Maier \& Mattos, 2016).

$\mathrm{Na}$ variável renda familiar, declararam renda de até 1 salário mínimo $\mathrm{n}=6(5,2 \%)$ e de 1 a 3 salários mínimos n=55 $(47,4 \%)$, totalizando $n=61(52,6 \%)$ dos estudantes, novamente corroborando com possibilidade do ingresso dessa população ao nível superior devido as políticas públicas que visam a diminuição das desigualdades sociais das minorias (Bublitz et al., 2015). Juntamente com a análise de que a maioria dos graduandos de Enfermagem trabalham e a renda familiar tem uma média baixa esse estudante precisa manter sua atividade laboral para colaborar no orçamento familiar, já que sua família possui recursos limitados e insuficientes para mantê-lo (Maier \& Mattos, 2016).

O quadro a seguir, dispõe das atividades diárias de vida dos estudantes a fim de auxiliar a desvelar o objetivo da pesquisa.

Quadro 2- Análise das atividades diárias dos graduandos de Enfermagem. Rio de Janeiro, Brasil, 2021.

\begin{tabular}{|l|l|}
\hline Atividades diárias & Total amostra $\mathbf{N}=\mathbf{1 1 6}(\mathbf{1 0 0 \%})$ \\
\hline $\begin{array}{l}\text { 1) Quem realiza as tarefas } \\
\text { domésticas }\end{array}$ & $\begin{array}{l}\text { O graduando } \mathrm{n}=33(27,6 \%) \rightarrow \text { Outra pessoa } \mathrm{n}=13(27,6 \%) \rightarrow \text { Todos da casa } \mathrm{n}=70 \\
(27,6 \%)\end{array}$ \\
\hline Tem ajudante particular & Sim $\mathrm{n}=10(8,6 \%) \rightarrow$ Não $\mathrm{n}=106(91,4 \%)$ \\
\hline $\begin{array}{l}\text { 2) Utiliza mais de um meio de } \\
\text { transporte por dia }\end{array}$ & Sim $\mathrm{n}=61(52,6 \%) \rightarrow$ Não $\mathrm{n}=55(47,4 \%)$ \\
\hline $\begin{array}{l}\text { Tempo estimado entre } \\
\text { casa x trabalho x universidade }\end{array}$ & $\begin{array}{l}\text { Até } 30 \text { minutos } \mathrm{n}=35(30,1 \%) \rightarrow 30 \text { a } 60 \text { minutos } \mathrm{n}=45(38,8 \%) \rightarrow 60 \text { a } 90 \text { minutos } \\
\mathrm{n}=14(12,1 \%) \rightarrow 120 \text { minutos } \mathrm{n}=16(13,8 \%) \rightarrow 180 \text { minutos } \mathrm{n}=2(1,8 \%) \rightarrow 240 \\
\text { minutos } \mathrm{n}=4(3,4 \%)\end{array}$ \\
\hline $\begin{array}{l}\text { 3) Tempo de lazer por semana } \\
(\text { em horas })\end{array}$ & $\begin{array}{l}\text { Menos de } 3 \text { horas } \mathrm{n}=32(27,6 \%) \rightarrow 3-5 \text { horas } \mathrm{n}=42(36,2 \%) \rightarrow 5-8 \text { horas } \mathrm{n}=22 \\
(19 \%) \rightarrow \text { Mais de } 8 \text { horas } \mathrm{n}=20(17,2 \%)\end{array}$ \\
\hline
\end{tabular}

Fonte: Autores (2021).

As tarefas domésticas em sua maioria são divididas entre todos os integrantes da casa $n=70$ (27,6\%), entretanto $n=33$ (27,6\%) dos graduandos realizam tais tarefas sem auxílio de outra pessoa. Ajudadores particulares são raros, já que n=106 $(91,4 \%)$ declaram não terem acesso a essa prestação de serviços. Esses dados mais uma vez reforçam a multiplicidade de obrigações diárias desses estudantes o que diminui seu tempo livre para descanso, convívio familiar e dedicação aos estudos, sendo mais um fator estressor que leva a diminuição da prática de autocuidado (Almeida et al., 2018; Fontana \& Brigo, 2012; Maier \& Mattos, 2016).

Quanto ao meio de transporte, $\mathrm{n}=61(52,6 \%)$ declararam a utilização de mais de um meio de transporte por dia, compreendendo um $\mathrm{n}=45(38,8 \%)$ de estudantes que levam em média de 30 a 60 minutos entre casa $\mathrm{x}$ trabalho $\mathrm{x}$ universidade, dobrando esse tempo se analisado tempo estimado gasto em ida e volta. Declaram ainda em sua maioria, no máximo 5 horas de lazer por semana se analisando os dois maiores percentuais que correspondem: $n=32(27,6 \%)$ com menos de 3 horas e $n=42$ $(36,2 \%)$ de 3 a 5 horas dedicadas ao lazer. A falta de tempo necessário para as atividades de lazer é uma das queixas desses trabalhadores e estudantes, já que estes mesmo quando estão em seu momento de folga, relatam se sentirem esgotados e desmotivados para a realização de qualquer atividade (Maier \& Mattos, 2016; Hirsch, Barlem, de Almeida, TomaschewskiBarlem, Lunardi \& Ramos,2018). 
Em sequência, quadro 3 representando as práticas de autocuidado dos graduandos de Enfermagem divididos em três períodos: antes da graduação, durante a graduação e na graduação com o advento da vivência de uma pandemia.

Quadro 3 - Prática autocuidado dos graduandos de Enfermagem antes da graduação, durante a graduação e no período de pandemia - Rio de Janeiro, Brasil, 2021.

\begin{tabular}{|c|c|c|c|}
\hline $\begin{array}{c}\text { Prática de autocuidado } \\
\text { Variáveis }\end{array}$ & Antes da graduação & Durante a graduação & Na pandemia \\
\hline 1) Quanto a ser saudável & $\begin{array}{l}\text { As vezes } n=45(38,8 \%) \rightarrow \\
\text { Poucas vezes } n=31(26,7 \%) \\
\rightarrow \text { Sempre } n=33(28,4 \%) \rightarrow \\
\text { Nunca } n=7(6 \%)\end{array}$ & $\begin{array}{l}\text { As vezes } \mathrm{n}=55(47,4 \%) \rightarrow \text { Poucas } \\
\text { vezes } \mathrm{n}=44(37,9 \%) \rightarrow \text { Sempre } \\
\mathrm{n}=15(12,9 \%) \rightarrow \text { Nunca } \mathrm{n}=2 \\
\quad(1,7 \%)\end{array}$ & $\begin{array}{l}\text { As vezes } n=39(33,6 \%) \rightarrow \\
\text { Poucas vezes } n=47(40,5 \%) \\
\rightarrow \text { Sempre } n=15(12,9 \%) \rightarrow \\
\text { Nunca } n=15(12,9 \%)\end{array}$ \\
\hline 2) Faz checkup de saúde & $\begin{array}{l}\operatorname{Sim} n=76(65,5 \%) \rightarrow \text { Não } \\
n=40(34,5 \%)\end{array}$ & $\begin{array}{l}\operatorname{Sim} n=79(68,1 \%) \rightarrow \text { Não } \\
n=37(31,9 \%)\end{array}$ & $\begin{array}{l}\text { Sim } n=52(44,8 \%) \rightarrow \text { Não } n= \\
64(55,2 \%)\end{array}$ \\
\hline $\begin{array}{l}\text { 3) Horas de sono por } \\
\text { Dia (atual) }\end{array}$ & ---------- & ----------- & $\begin{array}{r}4 \mathrm{~h} \mathrm{n}=6(5,2 \%) \rightarrow 5 \mathrm{~h} \mathrm{n}=19 \\
(16,4 \%) \rightarrow 6 \mathrm{~h} \mathrm{n}=31(26,7 \%) \\
\rightarrow 7 \mathrm{~h} \mathrm{n}=23(19,8 \%) \rightarrow 8 \mathrm{~h} \\
\mathrm{n}=27(23,3 \%) \rightarrow 9 \mathrm{~h} \text { ou mais } \\
\mathrm{n}=10(8,6 \%)\end{array}$ \\
\hline $\begin{array}{l}\text { Ininterruptas ou não } \\
\text { (atual) }\end{array}$ & ---------- & ---------- & $\begin{array}{l}\text { Sim } n=66(56,9 \%) \rightarrow \text { Não } n=50 \\
\quad(43,1 \%)\end{array}$ \\
\hline Isso foi afetado & ---------- & $\begin{array}{l}\text { Sim } n=90(77,6 \%) \rightarrow \text { Não } \\
n=26(22,4 \%)\end{array}$ & $\begin{array}{l}\text { Sim } n=72(62,1 \%) \rightarrow \text { Não } \\
n=44(37,9 \%)\end{array}$ \\
\hline $\begin{array}{l}\text { 4) Troca das refeições } \\
\text { principais por lanches } \\
\text { por semana }\end{array}$ & $\begin{array}{l}\text { Nenhuma } n=30(25,9 \%) \rightarrow \\
\text { Raramente } n=54(46,6) \rightarrow 2 \text { a } \\
3 \text { vezes } n=18(15,5 \%) \rightarrow 4 \text { a } 5 \\
\text { vezes } n=7(6 \%) \rightarrow \text { Mais de } 6 \\
\text { vezes } n=7(6 \%)\end{array}$ & $\begin{array}{l}\text { Nenhuma } n=15(12,9 \%) \rightarrow \\
\text { Raramente } n=18(15,5 \%) \rightarrow 2 \\
\text { a } 3 \text { vezes } n=33(28,4 \%) \rightarrow 4 \text { a } \\
5 \text { vezes } n=32(27,6 \%) \rightarrow \text { Mais } \\
\text { de } 6 \text { vezes } n=18(15,5 \%)\end{array}$ & $\begin{array}{l}\text { Nenhuma } n=26(22,4 \%) \rightarrow \\
\text { Raramente } n=24(20,7 \%) \rightarrow 2 \\
\text { a } 3 \text { vezes } n=34(29,3 \%) \rightarrow 4 \text { a } \\
5 \text { vezes } n=18(15,5 \%) \rightarrow \text { Mais } \\
\text { de } 6 \text { vezes } n=14(12,1 \%)\end{array}$ \\
\hline $\begin{array}{l}\text { 5) Ingesta de líquidos } \\
\text { por dia (água e sucos } \\
\text { naturais) }\end{array}$ & $\begin{array}{l}\text { Menos de } 1 \mathrm{~L} \mathrm{n}=14(77,6 \%) \rightarrow \\
1 \mathrm{~L} \mathrm{n}=43(77,6 \%) \rightarrow 2 \mathrm{~L} \mathrm{n}=46 \\
(77,6 \%) \rightarrow 3 \mathrm{~L} \mathrm{n}=\mathrm{n}=11 \\
(77,6 \%) \rightarrow \text { mais de } 3 \mathrm{~L} \mathrm{n}=2 \\
(77,6 \%)\end{array}$ & $\begin{array}{l}\text { Menos de } 1 \mathrm{~L} \mathrm{n}=6(5,2 \%) \rightarrow 1 \mathrm{~L} \\
\mathrm{n}=37(31,9 \%) \rightarrow 2 \mathrm{~L} \mathrm{n}=55 \\
(47,4 \%) \rightarrow 3 \mathrm{~L} \mathrm{n}=\mathrm{n}=16 \\
(13,8 \%) \rightarrow \text { mais de } 3 \mathrm{~L} \mathrm{n}=2 \\
(1,7 \%)\end{array}$ & $\begin{array}{l}\text { Menos de } 1 \mathrm{~L} \mathrm{n}=3(2,6 \%) \rightarrow \\
1 \mathrm{~L} \mathrm{n}=22(19 \%) \rightarrow 2 \mathrm{~L} \mathrm{n}=65 \\
(56 \%) \rightarrow 3 \mathrm{~L} \mathrm{n}=\mathrm{n}=22(19 \%) \\
\rightarrow \text { mais de } 3 \mathrm{~L} \mathrm{n}=4(3,4 \%)\end{array}$ \\
\hline 6) Consumo de cigarros & $\begin{array}{l}\text { Sim } \mathrm{n}=7(6 \%) \rightarrow \text { Não } \mathrm{n}=109 \\
(96 \%)\end{array}$ & $\begin{array}{l}\text { Sim } n=9(7,8 \%) \rightarrow \text { Não } n=107 \\
(92,2 \%)\end{array}$ & $\begin{array}{l}\text { Sim } n=8(6,9 \%) \rightarrow \text { Não } n=108 \\
(93,1 \%)\end{array}$ \\
\hline $\begin{array}{l}\text { 7) Consumo de bebidas } \\
\text { alcoólicas }\end{array}$ & $\begin{array}{l}\text { Sim } n=75(64,7 \%) \rightarrow \text { Não } \\
n=41(35,3 \%)\end{array}$ & $\begin{array}{l}\operatorname{Sim} n=77(64,4 \%) \rightarrow \text { Não } \\
n=39(33,6 \%)\end{array}$ & $\begin{array}{l}\text { Sim } n=63(54,3 \%) \rightarrow \text { Não } \\
n=53(45,7 \%)\end{array}$ \\
\hline 8) Uso de preservativos & $\begin{array}{l}\text { Sim } n=55(47,4 \%) \rightarrow \text { Não } \\
n=61(52,6 \%)\end{array}$ & $\begin{array}{l}\text { Sim } n=60(51,7 \%) \rightarrow \text { Não } \\
n=56(48,3 \%)\end{array}$ & $\begin{array}{l}\text { Sim } n=60(51,7 \%) \rightarrow \text { Não } \\
n=56(48,3 \%)\end{array}$ \\
\hline $\begin{array}{l}\text { 9) Uso de medicações } \\
\text { SEM prescrição }\end{array}$ & $\begin{array}{l}\operatorname{Sim} n=43(37,1 \%) \rightarrow \text { Não } \\
n=73(62,9 \%)\end{array}$ & $\begin{array}{l}\operatorname{Sim} n=49(42,2 \%) \rightarrow \text { Não } \\
n=67(57,8 \%)\end{array}$ & $\begin{array}{l}\operatorname{Sim} n=45(38,8 \%) \rightarrow \text { Não } \\
n=71(61,2 \%)\end{array}$ \\
\hline $\begin{array}{l}\text { 10) Crise de ansiedade/ } \\
\text { depressão }\end{array}$ & $\begin{array}{l}\operatorname{Sim} \mathrm{n}=38(32,8 \%) \rightarrow \text { Não } \\
\mathrm{n}=78(67,2 \%)\end{array}$ & $\begin{array}{l}\operatorname{Sim} n=90(77,6 \%) \rightarrow \text { Não } \\
n=26(22,4 \%)\end{array}$ & $\begin{array}{l}\operatorname{Sim} n=86(74,1 \%) \rightarrow \text { Não } \\
n=30(25,9 \%)\end{array}$ \\
\hline $\begin{array}{l}\text { Tratamento } \\
\text { Psicológico/psiquiátrico }\end{array}$ & $\begin{array}{l}\operatorname{Sim} n=19(16,4 \%) \rightarrow \text { Não } \\
n=97(83.6 \%)\end{array}$ & $\begin{array}{l}\text { Sim } n=80(69 \%) \rightarrow \text { Não } n=36 \\
(31 \%)\end{array}$ & $\begin{array}{l}\operatorname{Sim} n=97 \quad(83,6 \%) \rightarrow \text { Não } \\
n=19(16,4 \%)\end{array}$ \\
\hline Total & $n=166(100 \%)$ & $n=166(100 \%)$ & $n=166(100 \%)$ \\
\hline
\end{tabular}


Na variável 1, autopercepção da prática do autocuidado, pelo maior percentual, os estudantes relataram se sentirem saudáveis as vezes $n=45(38,8 \%)$ antes da graduação, as vezes $n=55(47,4 \%)$ durante a graduação e poucas vezes $n=47$ (40,5\%) durante a pandemia. O único percentual que obteve aumento gradual, antes da graduação até o momento de pandemia, foi poucas vezes; antes $n=31$ (26,7\%), durante vezes $n=44$ (37,9\%) e na pandemia $n=47$ (40,5\%). Quanto a sempre se sentirem saudáveis, obteve uma diminuição de mais de 50\% comparando do período antes da graduação até o período atual com a pandemia, se mantendo igual no período da graduação e com a pandemia; antes n=33 (28,4\%), durante $n=15(12,9 \%)$ e na pandemia $\mathrm{n}=15(12,9 \%)$. Quanto a nunca se sentirem saudáveis, ultrapassou o dobro do percentual da avaliação antes da graduação, $\mathrm{n}=7$ (6\%), em comparação com o período de pandemia, $\mathrm{n}=15$ (12,9\%), com diminuição significativa no período da graduação sem o advento da pandemia, $\mathrm{n}=2(1,7 \%)$.

Esses dados opõem-se a estudos anteriores onde os graduandos de Enfermagem declararam a prática do autocuidado e consideram-se satisfeitos com sua percepção de saúde durante a graduação (Almeida et al., 2018; Fontana \& Brigo, 2012; Maier \& Mattos, 2016; Campos, Oliveira, Silva, Otrenti \& Dias, 2019). Quanto ao período de pandemia, os autores não encontraram estudos que correlacionem a prática do autocuidado durante a graduação com o advento da pandemia e seus possíveis impactos, não sendo possível correlacioná-los. Entretanto, as análises do estudo sugerem que a multiplicidade de tarefas durante a graduação aliados ao estresse gerado pelo fator desconhecido de uma pandemia pode ter influenciado nessa percepção dos graduandos.

Quando abordados sobre a realização de exames clínicos periódicos de saúde (checkup de saúde), a maioria dos estudantes declaram realizarem checkup em dois períodos: o período antes da graduação representou um $\mathrm{n}=76(65,5 \%)$, durante a graduação $n=79(68,1 \%)$. Durante a pandemia houve uma reversão desse percentual com $n=64(55,2 \%)$ declarando não terem realizado checkup de saúde nesse período. Provavelmente relacionadas ao medidas de isolamento sociais, possíveis dificuldades financeiras devido ao fechamento de mais de meio milhão de empresas que decretaram falência devido a pandemia da Covid-19 no primeiro semestre de 2019, aliadas ao medo de adoecimento (Malta et al., 2020; Coelho et al., 2019; Instituto Brasileiro de geografia e Estatística, Pesquisa Pulso Empresa, 2019).

Salienta-se que, na variável 3 (horas de sono por dia) foram aplicadas 3 perguntas: horas de sono por dia (atual); se estas eram ininterruptas e se o estudante percebeu que a qualidade do seu sono foi afetada durante a graduação e ainda na graduação com advento da pandemia. Não havendo nesse bloco a necessidade de avaliação do período antes da graduação. A maioria declarou dormir em torno de seis horas $n=31(26,7 \%)$ por dia. No total da amostra $n=66(56,9 \%)$ declararam que essas horas eram ininterruptas. Avaliando o período da graduação antes da pandemia um n=90 $(77,6 \%)$ afirmou ter notado diferença na qualidade e horas de sono (Nunes, Leal, Marques \& Mendonça, 2017). Em tempo de pandemia um n=72 (62,1\%) declaram terem notado essa diferença analisando essa variável. Esse comparativo pode demonstrar que os graduandos perceberam melhora da qualidade e horas de sono no período de pandemia relaciona ao período da graduação antes dela.

Avaliando a troca das refeições principais por lanches por semana declararam que antes da graduação a maioria declarou que raramente tinha essa prática com $n=54(46,6)$, porém quando avaliado o período da graduação o maior percentual ficou na troca de 2 a 3 vezes por semana com $n=33(28,4 \%)$ e no período da pandemia este também foi o maior percentual com 2 a 3 vezes $n=34$ (29,3\%) (Urbanetto et al., 2019). No período antes da graduação pode-se constatar melhor prática nessa variável e avaliando todas as respostas possíveis do período da graduação comparando com o período da pandemia houve uma discreta melhora nas boas práticas de alimentação no período pandêmico, sugerindo que a sobrecarga oriunda da graduação leva a substituição da alimentação saudável por lanches rápidos, provavelmente associada ao fator tempo.

$\mathrm{Na}$ ingesta de líquidos como água e sucos naturais por dia os três períodos obtiveram um percentual satisfatório com a maioria da amostra declarando ingerirem um total de dois litros destes líquidos por dia. O Ministério da Saúde orienta a importância da ingesta de água própria para o consumo humano e sucos não adoçados, não sendo recomendado a substituição 
de frutas por sucos naturais, pois tem diminuição do aproveitamento de nutrientes em comparação com frutas inteiras (Ministério da Saúde, Protocolos de uso do Guia alimentar para a população Brasileira na orientação alimentar, 2021).

Quanto ao tabagismo, todos os três períodos tiveram quase o total da amostra negando sua prática com n=109 (96\%) antes da graduação, $\mathrm{n}=107(92,2 \%)$ e $\mathrm{n}=108(93,1 \%)$ na pandemia. No entanto, no consumo de bebidas alcoólicas a maioria declara o consumo nos três períodos avaliados, sendo estes: antes da graduação foi de $n=75$ (64,7\%), na graduação $n=77$ $(64,4 \%)$ e na pandemia $n=63(54,3 \%)$. Esses dados colaboram com a afirmativa que a maioria dos estudantes de Enfermagem fazem uso de bebidas alcóolicas com regularidade como recursos de alívio de estresse ou para conseguirem dormir (Silva et al., 2020).

Uso de preservativos nas relações sexuais antes da graduação obteve $n=61(52,6 \%)$, durante a graduação $n=60$ $(51,7 \%)$ declararam seu uso, igualmente na pandemia com $n=60(51,7 \%)$. Vale ressaltar que, um $n=23(19,8 \%)$ da amostra declaram serem casados e/ou possuírem algum tipo de união estável, o que acaba contribuindo para a diminuição do uso de preservativos por estes sentirem maior segurança na estabilidade dos seus relacionamentos. A falta de uso ou a prática de negociação sobre o uso de preservativos entre parceiros sexuais casuais ou fixos pode favorecer a exposição às infecções sexualmente transmissíveis (Spindola et al.,2020).

No uso de medicamentos sem prescrição médica os três períodos avaliados tiveram a maioria da amostra negando a prática, compreendendo: antes da graduação $n=97$ (83.6\%), durante a graduação $n=67(57,8 \%)$ e na pandemia $n=71(61,2 \%)$, o que contribui com pesquisas anteriores. Entretanto da parcela de graduandos que afirmaram fazerem uso de medicamentos sem prescrição, foram citaram os mais diversos medicamentos, desde analgésicos até antibióticos e ansiolíticos (Silva et al., 2020).

$\mathrm{Na}$ amostra um total de $\mathrm{n}=78(67,2 \%)$ declararam não terem sofrido crises de ansiedade e/ou depressão antes da graduação, quando questionados sobre o período da graduação $\mathrm{n}=90$ (77,6\%) afirmaram episódios dessa natureza e $\mathrm{n}=86$ $(74,1 \%)$ durante a pandemia, comprovando uma mudança brusca com impacto na saúde mental desses graduandos. Ainda nessa variável foi avaliado histórico de tratamento para estas patologias e um n=97 (83.6\%) declararam nunca terem buscado ajuda profissional neste sentido, já n=80 (69\%) declararam terem buscado tratamento no período da graduação e n=97 (83,6\%) no período de pandemia. Esses dados demonstram que apesar da maioria já ter passado por crises de ansiedade e depressão no período da graduação antes da pandemia foi no período da graduação durante a pandemia que houve uma maior procura por ajuda especializada.

As situações estressoras experimentadas ao longo da graduação podem influenciar no surgimento de distúrbios de humor como ansiedade e depressão, apesar de serem frequentemente encontrados problemas mentais em estudantes associados a vida acadêmica, muitos resistem ao tratamento por medo e insegurança em demonstrar sua fragilidade perante a sociedade. A baixa adesão ao tratamento, gera um grande desafio aos profissionais da saúde mental, uma vez que estes estudantes podem sofrer com piora das condições clínicas e agravamento do caso ocorrendo comprometimento da qualidade de vida (Almeida et al., 2018; Hirsch et al., 2018). 
Quadro 4 -Relacionamento interpessoal e dedicação aos estudos dos graduandos de Enfermagem durante a graduação e no período de pandemia - Rio de Janeiro, Brasil, 2021.

\begin{tabular}{|c|c|c|}
\hline Variáveis & Durante a graduação & Na pandemia \\
\hline $\begin{array}{l}\text { 1) Acolhimento pelos } \\
\text { docentes }\end{array}$ & $\begin{array}{l}\text { As vezes } n=31(26,7 \%) \rightarrow \text { Poucas vezes } \\
n=62(53,4 \%) \rightarrow \text { Sempre } n=19(16,4 \%) \\
\rightarrow \text { Não se aplica } n=4(3,5 \%)\end{array}$ & $\begin{array}{l}\text { As vezes } n=42(36,2 \%) \rightarrow \text { Poucas vezes } \\
n=39(33,6 \%) \rightarrow \text { Sempre } n=22(19 \%) \rightarrow \\
\text { Não se aplica } n=13(11,2 \%)\end{array}$ \\
\hline 2) Fez amizades & $\operatorname{Sim} n=112(96,6 \%) \rightarrow$ Não $n=4(3,4 \%)$ & Sim $n=69(59,5 \%) \rightarrow$ Não $n=47(40,5 \%)$ \\
\hline $\begin{array}{l}\text { 3) Horas dedicadas } \\
\text { aos estudos por dia }\end{array}$ & $\begin{array}{l}\text { Impossibilidade de quantificar } \mathrm{n}=5 \\
(4,3 \%) \rightarrow \text { Nenhuma } \mathrm{n}=0(0 \%) \rightarrow \text { Até } \\
1 \mathrm{~h} \mathrm{n}=9(7,8 \%) \rightarrow 2 \mathrm{~h} \mathrm{n}=31(26,7 \%) \rightarrow \\
3 \mathrm{~h} \mathrm{n}=20(17,2 \%) \rightarrow 4 \mathrm{~h} \mathrm{n}=18(15,5 \%) \\
\rightarrow 5 \mathrm{~h} \mathrm{n}=20(17,2 \%) \rightarrow 6 \mathrm{~h} \mathrm{n}=10(8,6 \%) \\
\rightarrow 7 \mathrm{~h} \mathrm{n}=0(0 \%) \rightarrow 8 \mathrm{~h} \mathrm{n}=1(0.9 \%) \rightarrow 9 \mathrm{~h} \\
\mathrm{n}=2(1,8 \%) \rightarrow 10 \mathrm{~h} \text { ou mais } \mathrm{n}=0(0 \%)\end{array}$ & $\begin{array}{l}\text { Impossibilidade de quantificar } \mathrm{n}=4(3,4 \%) \\
\rightarrow \text { Nenhuma } \mathrm{n}=11(9,5 \%) \rightarrow \text { Até } 1 \mathrm{~h} \mathrm{n}=24 \\
(20,7 \%) \rightarrow 2 \mathrm{~h} \mathrm{n}=27(23,3 \%) \rightarrow 3 \mathrm{~h} \mathrm{n}=10 \\
(8,6 \%) \rightarrow 4 \mathrm{~h} \mathrm{n}=15(12,9 \%) \rightarrow 5 \mathrm{~h} \mathrm{n}=5 \\
(4,3 \%) \rightarrow 6 \mathrm{~h} \mathrm{n}=6(5,2 \%) \rightarrow 7 \mathrm{~h} \mathrm{n}=4 \\
(3,4 \%) \rightarrow 8 \mathrm{~h} \mathrm{n}=5(4,3 \%) \rightarrow 9 \mathrm{~h} \mathrm{n}=1(0,9 \%) \\
\rightarrow 10 \mathrm{~h} \text { ou mais } \mathrm{n}=4(3,4 \%)\end{array}$ \\
\hline 4) Acúmulo de matérias & $\begin{array}{l}\text { As vezes } n=29(25 \%) \rightarrow \text { Poucas vezes } \\
n=54(46,6 \%) \rightarrow \text { Sempre } n=22(19 \%) \rightarrow \\
\text { Não se aplica } n=11(9,5 \%)\end{array}$ & $\begin{array}{l}\text { As vezes } n=32(27,2 \%) \rightarrow \text { Poucas vezes } \\
n=32(27,2 \%) \rightarrow \text { Sempre } n=40(34,5 \%) \rightarrow \\
\text { Não se aplica } n=12(10,2 \%)\end{array}$ \\
\hline Total & $n=166(100 \%)$ & $n=166(100 \%)$ \\
\hline
\end{tabular}

Fonte: Autores (2021).

Quanto ao relacionamento interpessoal, foram avaliadas duas variáveis: sentimento de acolhimento pelos docentes e se fez amizades. Estas foram avaliadas em dois períodos: durante a graduação e durante a pandemia. Os graduandos em sua maioria afirmaram se sentirem poucas vezes acolhidos com um $n=62(53,4 \%)$ durante a graduação e na pandemia um $n=42$ $(36,2 \%)$ declararam as vezes se sentiam acolhidos. E referente a terem feito amizades na graduação um total de $\mathrm{n}=112(96,6 \%)$ fizeram amizades e $n=69(59,5 \%)$ declararam terem feito amizades durante o período da pandemia.

É importante para os estudantes conseguirem manter um bom relacionamento interpessoal com seus professores e seus colegas de curso, formando uma boa rede de apoio. O diálogo aberto e a demonstração de interesse por parte do professor na adaptação acadêmica e na formação desses estudantes quebram barreiras e medos da transição do ensino médio para o ensino universitário, despertando seu interesse e melhorando seu desempenho nas disciplinas ao longo da graduação. Já estudantes que fizeram amizades ao longo da graduação tem menos riscos de adiamento ou desistência do curso. Cooperação e amizade fortalece o vínculo entre estudantes universitários, sendo os conflitos um fator limitador a rede de apoio desses estudantes, independentemente da sua inteligência e habilidades esse acadêmico terá maior tendência a evasão dos cursos em essa rede de apoio (Almeida et al., 2018; da Matta, Lebrão \& Heleno, 2017).

No que tange a dedicação aos estudos, foram avaliadas duas variáveis compreendendo: horas dedicadas aos estudos por dia e acúmulo de matérias. Nos dois períodos houve respostas que não eram referentes a horários e estes foram classificados como impossíveis de quantificar. Relataram estudar durante a graduação com n=31 (26,7\%) em média 2 horas, seguidos por 3 e 5 horas com $n=20(17,2 \%)$ respectivamente e na pandemia $n=27(23,3 \%)$ com média de duas horas e com $\mathrm{n}=24(20,7 \%)$ com média de uma hora, seguido por $\mathrm{n}=15(12,9 \%)$ com média de quatro horas por dia. Nenhum dos dois períodos avaliados atingiu um terço da amostra, comprovando a falta de consistência nessas variáveis, sem um percentual expressivo da amostra. 
Os estudantes muitas vezes se culpam por não conseguirem dedicação plena aos estudos, realização das atividades exigidas nas disciplinas e dificuldade de manter uma boa rotina de estudos devido as múltiplas demandas do dia a dia. A sobrecarga de obrigações gera sentimento de incapacidade, estresse e tristeza que a longo prazo propiciam o surgimento de crises de ansiedade e depressão (Bernardino et al., 2018).

No período da pandemia ocorreu um fenômeno intrigante, tendo em vista que nenhum graduando afirmou não ter dedicado nenhuma hora dedicada aos estudos e nem mais que dez horas ou mais durante a graduação e quando questionados das horas dedicadas aos estudos na pandemia surgiu um $n=11(9,5 \%)$ relatando nenhuma hora dedicada e $n=4(3,4 \%)$ com dez horas ou mais. Os dados podem salientar por uma mudança brusca de comportamento em alguns estudantes com o fator pandemia, uns aproveitando o máximo o fato de estarem estudando de modo virtualizado e outros com algum fator impeditivo, podendo ser por questões emocionais, levando-os a não estudarem.

Afirmaram ainda, quanto ao acúmulo de matérias, durante a graduação um total de n=54 (46,6\%) relataram acúmulo de matérias poucas vezes, seguido de $n=29$ (25\%) poucas vezes. Enquanto na pandemia um total de $n=40(34,5 \%)$ declararam sempre acumularem matérias, seguido de um $n=32(27,2 \%)$ com relato de poucas vezes. A virtualização das disciplinas alterou a rotina diária dos estudantes, sabendo-se que tais alterações geram estresse, podendo levar a alteração de comportamento com o acúmulo de matérias (perda de foco acadêmico) e interferir diretamente na sua saúde mental (Almeida, 2018).

A seguir, diante da organização e análise dos dados qualitativos, processo realizado em etapas através de leitura transversal e das observações de palavras, frases e/ou conceitos similares e mais frequentes emergiram quatro categorias compreendidas em: conceito saúde e sua correlação com a prática autocuidado do indivíduo; mudança da percepção do conceito saúde e sua influência na prática do autocuidado do graduando de Enfermagem; importância da qualidade de formação e prática do autocuidado na percepção do aproveitamento da graduação de Enfermagem e autoavaliação da aptidão para o mercado de trabalho sob a interferência da multiplicidade de variáveis na formação do graduando de Enfermagem.

A categoria I, conceito saúde e sua correlação com a prática autocuidado do indivíduo, nos possibilitou analisar a percepção do indivíduo inserido na sociedade sobre o que é autocuidado antes do ingresso em um curso de nível superior da área da saúde.

A categoria II, mudança da percepção do conceito saúde e sua influência na prática do autocuidado do graduando de Enfermagem, nos possibilitou avaliar se o aprimoramento do conceito saúde a partir da vivência da graduação é capaz de influenciar na prática do autocuidado do estudante de Enfermagem.

A categoria III, importância da qualidade de formação e prática do autocuidado na percepção do aproveitamento da graduação de Enfermagem, nos possibilitou avaliar a percepção do graduando acerca do aproveitamento dos seus estudos através das múltiplas variáveis analisadas.

\section{Categoria I - Conceito saúde e sua correlação com a prática autocuidado do indivíduo}

É de extrema importância que o indivíduo possua conhecimento acerca da sua saúde e para isso é fundamental que este conheça todas as nuances que envolvem a prática do autocuidado. Muitas vezes o significado de ter saúde é comumente confundido com a ausência de doença física e diante da sua ausência acaba ocorrendo uma visão errônea que pode incorrer em displicência de outras interfaces relacionadas a saúde que a longo prazo podem ser desencadeadoras de doenças.

\section{"[...] Ter bem-estar fisico, mental e social” (Grad.3).}

"[...] Ser saudável é ter saúde fisica para desenvolver as atividades diárias e saúde emocional para lidar com as pressões do cotidiano" (Grad.32). 
“[...] É estar bem fisicamente, mentalmente e socialmente” (Grad.34).

“[...] Uma pessoa saudável é estar psicologicamente, fisicamente e socialmente” (Grad.53).

“[... É uma pessoa que tem saude, vida pessoal e profissional boa” (Grad.56).

"[...] Aquela que está bem fisicamente, psicologicamente, socialmente e ausente de doença" (Grad.66).

"[...] Individuo que se encontra em completo bem-estar físico e psicológico" (Grad.74).

“[...] Completo bem-estar físico, mental, social e não somente ausência de enfermidades” (Grad.87).

“[...] Uma pessoa com bons hábitos alimentares, que prática algum tipo de esporte diariamente. Além do bem-estar físico e mental" (Grad.93).

A Organização Mundial da Saúde, em 1946, amplificou o conceito de saúde como um estado de completo bem-estar físico, mental e social que visa garantir o nível mais elevado de saúde (Constituição da Organização Mundial de Saúde, OMS/WHO, 1946). Antes do conhecimento passado ao longo da graduação os estudantes de Enfermagem demostraram que como a maioria da população declaravam essa frase de forma repetitiva, porém sem conhecimento sobre suas garantias e direitos referente ao item saúde, incluindo o objetivo de formar uma opinião pública esclarecida a todos os povos sobre assuntos de saúde. A falta de conhecimento sobre a amplitude do conceito saúde implica diretamente na prática do autocuidado do indivíduo.

\section{Categoria II - Mudança da percepção do conceito saúde e sua influência na prática do autocuidado do graduando de} Enfermagem

A Enfermagem é uma profissão especializada no cuidado humano. Atua visando a saúde de forma integral do indivíduo e está presente desde o seu nascer até o seu morrer. Para que esses profissionais tenham entendimento da magnitude da sua atuação na vida do outro é necessário boa formação por parte das instituições de ensino, fundamentada em conhecimento teórico-científico e prático e conhecimento sobre a importância de se estar bem para conseguir garantir a qualidade da sua assistência.

“[...] Sim, antes eu não pensava tanto na importância da saúde mental” (Grad.5).

“[...] Não mudou completamente, ele foi melhorado, reformulado na minha cabeça; passei a ter uma visão mais ampla, que vai muito além das coisas que eu já como base ser uma pessoa saudável” (Grad.39).

"[...] Sim, antes considerava apenas a questão da doença física em si. Porém entendi que saúde vai muito além” (Grad.83).

“[...] Sim, antes acreditava que uma pessoa saudável era alguém que não tinha sinais e sintomas aparente de qualquer doença" (Grad.89).

"[...] Um pouco, pois antes pensava que não estar doente era sinal de estar saudável, mas na verdade não é assim” (Grad.101). 


\section{“[...] Sim, porque a princípio pensamos que saúde é ausência de doença. Hoje compreendo que posso considerar saudável a pessoa que mantém um equilibrio entre saúde física e mental" (Grad.102).}

Dentre as múltiplas variáveis que possam influenciar diretamente no conceito saúde definido pela OMS e garantido no Constituição de 1946 estão itens como: promover em cooperação com organismos especializados no melhoramento da alimentação, da habitação, do saneamento, do recreio, das condições econômicas e de trabalho e de outros fatores de higiene do meio ambiente e prevenção de danos por acidentes entre outros que em conjunto complementam o conceito ampliado de saúde e vão muito além de seu estado físico de saúde (Constituição da Organização Mundial de Saúde, OMS/WHO, 1946).

Já na Sessão da Saúde da Constituição da República Federativa do Brasil, de 1988, Art. 196 declara que saúde é um direito de todos e um dever do estado que deve ser garantida mediante políticas sociais e econômicas visando à redução do risco de doenças e de seus agravos com acesso universal e igualitário às ações e serviços de saúde com a promoção, proteção e recuperação a todo indivíduo que esteja dentro do território nacional (Constituição da República Federativa do Brasil, 1988).

Instituições de ensino superior de Enfermagem também são responsáveis pela saúde do seu estudante direta e indiretamente, pois além de serem responsáveis pela saúde do estudante nos estágios supervisionados desses estudantes, as instituições precisam obedecer as regras em sua formação que visam garantir a qualidade do processo de ensino-aprendizagem com corpo docente capacitado para o ensino desses novos Enfermeiros, cumprimento do plano pedagógico proposto, campos de estágios e respeito a carga horária exigida e declarada ao COREN, porque o ensino precário acarreta prejuízos ao profissional e ao paciente por ele atendido (Conselho Regional de Enfermagem, formação profissional com responsabilidade, 2008).

Lembrando que, a falta de suporte por parte da instituição de ensino também pode gerar estresse ao estudante levandoo a crises de ansiedade e depressão, o que afetaria a sua saúde mental, diminuiria sua capacidade de aprendizagem, diminuiria a sua prática de autocuidado e consequentemente, qualidade profissional (Hirsch et al., 2018).

\section{Categoria III - Importância da qualidade de formação e prática do autocuidado na percepção do aproveitamento da graduação de Enfermagem}

O aproveitamento do estudante de Enfermagem durante a graduação depende da qualidade de formação por parte da instituição de ensino superior e das múltiplas variáveis que quando positivas favorecem uma melhor qualidade de aprendizado. Quando essas variáveis são negativas desfavorecem o processo, limitando a qualidade da sua formação com baixo aproveitamento. Quanto ao aproveitamento os graduandos de Enfermagem, declararam de forma positiva n=59 (50,9) e $\mathrm{n}=47$ $(40,1 \%)$ de forma negativa o aproveitamento da graduação.

“[...] Sim, todas as oportunidades que foram oferecidas eu aproveitei, acredito que nos primeiros anos não, mas ao decorrer da graduação fui mudando meu comportamento estudantil e consegui aproveitar" (Grad.19).

"[...] Sim, porque estou trabalhando na área” (Grad.48).

“[...] Sim, pois tentava sugar ao máximo as explicações dos professores, participei de PIC, ligas acadêmicas, de simpósios e congressos" (Grad.70).

“[...]Sim. Porque todas minhas horas de descanso e lazer foram em prol de obter o máximo de experiência e conhecimento para fomentar meu currículo" (Grad.81). 
"[...] Sim, pelo fato de aproveitar as oportunidades de aprendizagem e estar sempre estudando e tirando dúvidas, buscando sempre aprender e ter uma formação melhor" (Grad.96).

"[...] Sim, além de adquirir conhecimento eu faço amizades, conheço pessoas e me relaciono socialmente"

(Grad.112).

Relacionando as falas dos graduandos de Enfermagem que tem a percepção de um bom aproveitamento da graduação com literaturas atualizadas, podemos notar a importância de se manter uma rotina de estudos aliadas a uma boa rede de apoiadores. Tão importante quanto o apoio no âmbito acadêmico, instituição e docentes e entre discente, a família e os amigos têm papel fundamental fazendo parte da rede de apoiadores informais, não diretamente ligados aos seus estudos, mas que também corroboram para o seu fortalecimento psíquico e equilíbrio emocional. Por outro lado, os estudantes com baixo apoio indicam situação de vulnerabilidade social, predizendo condições físicas e psicológicas deficientes. Lacunas na rede de apoio ao estudante de Enfermagem impactam negativamente no seu desenvolvimento acadêmico e social, deixando-o suscetível ao surgimento de doenças (Almeida et al., 2018; da Matta, Lebrão\& Heleno, 2017). Uma boa rede de apoio alivia o desgate emocional gerado pelo estresse da graduação, melhora a qualidade de vida e diminui a vulnerabilidade de saúde do estudante possibilitando melhores práticas de autocuidado (Almeida et al., 2018).

"[...] Não. Trabalho todos os dias, enfrento engarrafamento, tenho outros compromissos como minha terapia e atividade física para realizar, então acredito que poderia aproveitar mais a graduação se tivesse mais tempo hábil. Até para participar de projetos de extensão da faculdade" (Grad.2).

"[...] Não; porque minhas limitações psicossociais impõem barreiras que mitigam o total aproveitamento" (Grad.36).

"[...] Não. Acredito que a graduação não seja apenas estudos e sim conhecer pessoas novas, mas eu sempre tinha pressa de chegar em casa ao fim da aula, pois moro longe" (Grad.60)

"[...] O aproveitamento está um pouco limitado por conta da pandemia em relação as frequências das práticas que reduziram a 1 durante o período do semestre" (Grad.69).

"[...] Não, acredito que o tempo e a distância do lugar onde eu moro me desanimam a participar de alguns eventos e de me envolver mais com outros projetos" (Grad.79).

“[...] Não muito, sinto sempre que preciso fazer mais, e ao mesmo tempo sinto que não consigo” (Grad.95).

Por outro lado, o graduando que afirma ter que se dividir entre estudos e emprego formal com horas desperdiçadas em meios de transportes devido a longa distância entre casa, trabalho, universidade em conjunto com outras tarefas diárias como obrigações do lar e cuidados dos filhos tem menor percepção de aproveitamento da graduação (Almeida et al., 2018; da Matta, Lebrão\& Heleno, 2017). A frustação de não estar cumprindo com seu dever e as mudanças bruscas na rotina do estudante agravadas com a dessocialização e medos ligados a pandemia são fatores estressores e geradores de doenças, não sobrando tempo para esse estudante dedicar em prol de si mesmo e de suas necessidades de autocuidado (Aquino et al.,2020; Malta et al., 2020; Almeida et al., 2018; Fontana \& Brigo, 2012; Maier \& Mattos, 2016). 
Segundo a Teoria do Autocuidado de Dorothea Orem, o autocuidado é toda ação do indivíduo em benefício próprio que colabora para o seu crescimento, desenvolvimento e integridade, porém está prática está sujeita a várias condicionantes que abrangem características pessoais, fatores ambientais, capacidade de adaptação e disponibilidades dos recursos necessários a manutenção da vida (Mcewen \& Wills, p.133-161, 2016). A graduação é parte do desenvolvimento humano e exige do estudante essa capacidade de adaptação mesmo na vivência de várias condicionantes que podem influenciar diretamente em sua capacidade de autocuidado. O profissional Enfermeiro é constantemente exposto a situações estressoras que demandam capacidade de resiliência com a habilidade de desenvolver técnicas que possibilitam melhores condições físicas e emocionais para sua atuação (Mello et al., 2021).

Os graduandos de Enfermagem demostram grande ansiedade em relação a sua capacitação prática. O medo de não estar preparado e não ser absorvido pelo mercado de trabalho após cinco anos dedicados aos estudos é notória e ao mesmo tempo ocorre a preocupação em causar algum dano durante sua assistência. As instituições de ensino superior de Enfermagem precisam manter constante qualidade do processo de ensino-aprendizagem, inclusive dos estágios supervisionados obrigatórios, obedecendo as regras impostas pelo COREN na formação de seus discentes (Conselho Regional de Enfermagem, formação profissional com responsabilidade, 2008). As medidas restritivas impostas devido a pandemia com a necessidade da virtualização das disciplinas e paralisação dos estágios supervisionados dificultou esse cumprimento, no entanto aos poucos instituição e graduandos estão vencendo barreiras e retornando ao campo prático, ainda com algumas restrições, comprovando a capacidade de resiliência da Enfermagem no enfrentamento a pandemia (Malta et al., 2020).

As instituições de nível superior de Enfermagem têm a necessidade de ampliar o conhecimento do aluno acerca do conceito saúde para que este seja capaz de cuidar de forma integral e individualizada, sendo notório esse conhecimento entre os graduandos, já que estes não serão só cuidadores, mas também educadores da população e de sua equipe (Conselho Regional de Enfermagem, formação profissional com responsabilidade, 2008). Entretanto, os achados demostram que ocorre dificuldade desses estudantes de colocarem em prática tais conhecimentos em benefício da sua própria saúde. Tal fenômeno ocorre devido a multiplicidade de demandas as quais o estudante desenvolve diariamente, dificultando a prática efetiva do autocuidado. Conciliar estudos e trabalho formal, tarefas domésticas, dedicação a família entre tantos outros afazeres são desgastantes e geradoras de estresse, impedindo o pleno aproveitamento da graduação (da Matta, Lebrão \& Heleno, 2017; Fontana, R. T., \& Brigo, L. (2012).

\section{Conclusão}

Esta pesquisa atingiu seu objetivo desvelando as dificuldades enfrentadas na prática do autocuidado pelos graduandos de Enfermagem durante a graduação presencial, avaliando como seu pior fator o estresse advindo da necessidade de estudar em concomitância com atividade laboral. A necessidade de manter o vínculo empregatício gera múltiplas situações problemas que levam o estudante ao esgotamento físico e emocional que propiciam crises de ansiedade e depressão. Na avaliação do autocuidado durante a pandemia com a virtualização das disciplinas o principal fator estressor que dificulta a prática do autocuidado é a mudança brusca na rotina dos estudantes, agravando quadros de ansiedade e depressão, seguido por medo de não conseguir ter conhecimento prático necessário à sua formação por causa da virtualização das disciplinas e restrições nas atividades de estágio supervisionado obrigatório.

A partir das dificuldades enfrentadas propõem-se que as instituições de ensino superior de Enfermagem promovam um ambiente acolhedor direcionado aos seus estudantes com local destinado a escuta especializada na prevenção dos possíveis agravos a saúde referentes as variáveis avaliadas nesse estudo. Promovam ainda, a inserção precoce desses estudantes no campo prático por meio de estágios supervisionados obrigatórios externos com cuidado direto a população, conferindo melhor 
qualidade no processo de ensino-aprendizagem, conferindo confiança a esse estudante no momento de transição de estudante a profissional Enfermeiro e melhor oportunidade na inserção no mercado de trabalho.

Sugere-se outros estudos com ampla avaliação das variáveis que podem dificultar a prática do autocuidado dos graduandos de Enfermagem e estudos que venham a avaliar o impacto da vivência de uma pandemia na prática de autocuidado desses estudantes, a fim de evitar agravos a saúde com evasões do curso e/ou a inserção desse novo profissional ao mercado de trabalho em condição de saúde física e psicológica deficiente. É de fundamental importância que o enfermeiro seja capaz de praticar o autocuidado, sendo promotor de saúde para si e para os outros, como proposto por Dorothea Orem em sua teoria do autocuidado, posto que sua saúde está intrinsecamente relacionada a sua capacidade de prestar assistência de qualidade.

\section{Referências}

Almeida, L. Y. de, Carrer, M. O., Souza, J. de, \& Pillon, S. C. (2018). Avaliação do apoio social e estresse em estudantes de enfermagem. Revista Da Escola de Enfermagem Da USP, 52(0), 1-8. https://doi.org/10.1590/s1980-220x2017045703405

Aquino, E. M. L., Silveira, I. H., Pescarini, J. M., Aquino, R., \& de Souza-Filho, J. A. (2020). Social distancing measures to control the COVID-19 pandemic: potential impacts and challenges in Brazil. Ciencia e Saude Coletiva, 25, 2423-2446. https://doi.org/10.1590/1413-81232020256.1.10502020

Barboza, N. S. R., Fassarella, C. S.\& Souza, P. A. de. (2020). Self-care by discalced carmelite nuns in the light of Orem 's Theory *. Rev Esc Enferm USP, $54, \mathrm{e} 03637$.

Bardin. L, (2016). Análise de conteúdo (70 Ed. LDA). Lisboa, Portugal.

Bernardino, A. de O., Coriolano-Marinus, M. W. de L., Santos, A. H. da S., Linhares, F. M. P., Cavalcanti, A. M. T. de S., \& de Lima, L. S. (2018). Motivação dos estudantes de enfermagem e sua influência no processo de ensino-aprendizagem. Texto e Contexto Enfermagem, 27(1), 1-10. https://doi.org/10.1590/0104-070720180001900016

Bublitz, S., Guido, L. de A., Kirchhof, R. S., Neves, E. T., \& Lopes, L. F. D. (2015). Perfil sociodemográfico e acadêmico de discentes de enfermagem de quatro instituições brasileiras. Revista Gaúcha de Enfermagem, 36(1), 77-83.

Campos, C. M. S., Oliveira, J. P. de S., Silva, S. G., Otrenti, E., \& Dias, V. F. G. (2019). Desgastes e fortalecimentos de graduandos de enfermagem expressos em mídia social: uma análise potencializadora de ações de enfrentamento. Rev Med, 98(2), 0-5.

Coelho, M. T. Á. D., Carvalho, V. P. De, \& Porcino, C. (2019). Representações sociais de doença , usos e significados atribuídos às Práticas Integrativas e Complementares por universitários. SAÚDE DEBATE |, 43(122), 848-862. https://doi.org/10.1590/0103-1104201912215

Conselho Federal de Enfermagem (2021). Enfermagem em números - Quantitativo de profissionais por regional. Recuperado em 23 abril de 2021, http://www.cofen.gov.br/enfermagem-em-numeros.

Conselho Federal de Enfermagem (2020). Parecer de Câmara Técnica Nº14/2020/CTAS/COFEN, de 08 junho de 2020. Seringas autorretráteis. Redução de acidentes de trabalho. Recuperado em 23 abril de 2021,http://www.cofen.gov.br/parecer-no-014-2020-cofen-ctas_80477.html

Conselho Regional de Enfermagem (2008). Formação profissional com responsabilidade? o que os cursos de Enfermagem deixam de mostrar aos alunos. Revista COREN-SP $n^{\circ}$ 73, ISSN 1806-5473, janeiro/fevereiro de 2008. Recuperado em 23 de abril de 2021, https://portal.corensp.gov.br/sites/default/files/73_0.pdf

Conselho Regional de Enfermagem (2021).Pandemia de Covid19 - março-2020/março-2021: um ano de dor e luta na Enfermagem, 10 de março de 2021. Uma homenagem do COREN-RJ aos profissionais da Enfermagem pela atuação no maior desafio de nossas vidas. Recuperado em 26 abril de 2021 , de http://rj.corens.portalcofen.gov.br/pandemia-de-covid19-marco-2020-marco-2021-um-ano-de-dor-e-luta-na-enfermagem_21228.html

Constituição da República Federativa do Brasil 1988. (1988). Jusbrasil.https://presrepublica.jusbrasil.com.br/legislacao/91972/constituicao-da-republicafederativa-fazer-brasil-1988\#art-226

Constituição da Organização Mundial de Saúde (1946). OMS/WHO. Recuperado em 27 abril de 2020, de http://www.direitoshumanos.usp.br/index.php/OMSOrganiza\%C3\%A7\%C3\%A3o-Mundial-da-Sa\%C3\%BAde/constituicao-da-organizacao-mundial-da-saude-omswho.html

Costa, C. M. A., Matta, T. F., Santos, E. C. dos J., Araujo, L. M. de, Martins, E. R. C., \& Spíndola, T. (2020). Saberes e práticas de alunos de enfermagem na atenção à saúde das minorias sexuais. Glob Acad Nurs., 1(3), 1-7.

da Matta, C. M. B., Lebrão, S. M. G., \& Heleno, M. G. V. (2017). Adaptação, rendimento, evasão e vivências acadêmicas no ensino superior: revisão da literatura. Psicologia Escolar e Educacional, 21(3), 583-591. https://doi.org/10.1590/2175-3539/2017/0213111118

da Silva, M. C. N., \& Machado, M. H. (2020). Sistema de Saúde e Trabalho: desafios para a Enfermagem. Ciencia e Saude Coletiva, 25(1), 7-13. https://doi.org/10.1590/1413-81232020251.27572019

Fontana, R. T., \& Brigo, L. (2012). Estudar e trabalhar: percepções de técnicos de enfermagem sobre esta escolha. Escola Anna Nery, 16(1), 128-133. https://doi.org/10.1590/s1414-81452012000100017

Giovannini, P. E., Pontes, L., \& Carlos, N. (1981). O Caminho se Faz ao Caminhar : Novas Perspectivas da Educação Médica no Contexto da Pandemia The 
Path Is Made by Walking it: New Perspectives for Medical Education in the Pandemic Context. 44, 1-8.

Hirsch, C. D., Barlem, E. L. D., de Almeida, L. K., Tomaschewski-Barlem, J. G., Lunardi, V. L., \& Ramos, A. M. (2018). Fatores percebidos pelos acadêmicos de enfermagem como desencadeadores do estresse no ambiente formativo. Texto e Contexto Enfermagem, 27(1), 1-11. https://doi.org/10.1590/0104-07072018000370014

Instituto Brasileiro de geografia e Estatística (2013). Características étnico-raciais da população: classificações e identidades. Brasil: IBGE. Recuperado em 23 abril de 2021, de https://biblioteca.ibge.gov.br/visualizacao/livros/liv63405.pdf

Instituto Brasileiro de geografia e Estatística (2010). Censo Demográfico 2010.Brasil: IBGE. Recuperado em 23 abril de 2021, de https://censo2010.ibge.gov.br/resultados

Instituto Brasileiro de geografia e Estatística (2019). Pesquisa Pulso Empresa: Impacto da COVID-19 nas empresas.Brasil: IBGE. Recuperado em 23 abril de 2021, de https://agenciadenoticias.ibge.gov.br/media/com_mediaibge/arquivos/548281f191c80ecbbb69846b0d745eb5.pdf

Knechtel, M.R. (2014). Metodologia da pesquisa em educação: uma abordagem teórico-prática dialogada. Curitiba, PR: Intersaberes.

Maier, S. R. de O., \& Mattos, M. De. (2016). O Trabalhar e o estudar no contexto universitário: uma abordagem com trabalhadores-estudantes. Saúde (Santa Maria), 42(1), 179. https://doi.org/10.5902/2236583420477

Malta, D. C., Szwarcwald, C. L., Barros, M. B. de A., Gomes, C. S., Machado, Í. E., Souza Júnior, P. R. B. de, Romero, D. E., Lima, M. G., Damacena, G. N., Pina, M. de F., Freitas, M. I. de F., Werneck, A. O., Silva, D. R. P. da, Azevedo, L. O., \& Gracie, R. (2020). A pandemia da COVID-19 e as mudanças no estilo de vida dos brasileiros adultos: um estudo transversal, 2020. Epidemiologia e Serviços de Saúde, 29(4), 1-13. https://doi.org/10.1590/s167949742020000400026

Mcewen, M \& Wills, E. (2016). Bases teóricas de enfermagem. Capítulo: Grandes teorias da enfermagem baseadas nas necessidades humanas (4 th edição, p.133-161). Porto Alegre: Artmed.

Melo, T. C. L. C. ., Sampaio, A. C. C. de ., Albuquerque Neto, F. W. de ., Santos, J. L. R. dos ., Alves, P. C. ., Gadelha, L. de A. ., Costa, S. de S. V. ., Araújo, C. R. de C. e ., Vasconcelos, A. K. C., \& Ferreira, F. V. . (2021). Cuidando do cuidador: Um relato de experiência de intervenções de boas práticas de saúde para profissionais da atenção primária da linha frente na COVID-19. Research, Society and Development, 10(5), e14110515007. https://doi.org/10.33448/rsdv10i5.15007

Ministério da Saúde (2021). Protocolos de uso do Guia alimentar para a população Brasileira na orientação alimentar: bases teóricas e metodológicas e protocolo para a população adulta. Brasília, Distrito Federal: MS. Recuperado em 29 abril de 2021 de http://bvsms.saude.gov.br/bvs/publicacoes/protocolos_guia_alimentar_fasciculo1.pdf

Nogueira, M., Silva, L., Reis R., David, R., Leal, H. \& Docile, T. (2021, março). $1^{\circ}$ Boletim da Pesquisa Monitoramento da saúde, acesso à EPIs de técnicos de enfermagem, agentes de combate às endemias, enfermeiros, médicos e psicólogos, no município do Rio de Janeiro em tempos de Covid-19. Rio de Janeiro, RJ: EPSJV/FIOCRUZ. Recuperado em 26 abril de 2021, de https://www.arca.fiocruz.br/bitstream/icict/46369/2/boletim_pesquisa.pdf

Nunes, M. G. S., Leal, M. C. C., Marques, A. P. de O., \& Mendonça, S. de S. (2017). Idosos longevos : avaliação da qualidade de vida no domínio da espiritualidade, da religiosidade e de crenças pessoais. SAÚDE DEBATE |, 41(115), 1102-1115. https://doi.org/10.1590/0103-1104201711509

Rodríguez Gómez, M., Trespalacios Ferreira, V., Gutiérrez Blanco, M. A., Villamizar Osorio, M. L., \& Torres, C. C. (2018). Agencia de autocuidado, conocimientos, actitudes y prácticas de riesgo biológico en estudiantes de enfermería. Revista Cuidarte, 10(1), 1-9. https://doi.org/10.15649/cuidarte.v10i1.622

Santos, T. C. de M. M. dos, Martino, M. M. F. De, Sonati, J. G., Faria, A. L. De, \& Nascimento, E. F. de A. (2016). Qualidade do sono e cronotipo de estudantes de enfermagem. Acta Paulista de Enfermagem, 29(6), 658-663. https://doi.org/10.1590/1982-0194201600092

Silva, K. K. M. da, Martino, M. M. F. de, Bezerra, C. M. B., Nunes, J. T., Souza, Â. M. L. de, \& Silva, D. M. da. (2020).Estresse e qualidade do sono em alunos de graduação em Enfermagem. Rev Bras Enferm., 73(Suppl 1), e20180227. https://doi.org/10.1590/0034-7167-2018-0227

Spindola, T., Oliveira, C. S. R., Costa, D. M. da, André, N. L. N. de O., Motta, C. V. V. da, \& Melo, L. D. de. (2020). Uso e negociação de preservativos por acadêmicos de enfermagem. Rev Recien, 10(32), 81-91.

Urbanetto, J. de S., da Rocha, P. S., Dutra, R. C., Maciel, M. C., Bandeira, A. G., \& Magnago, T. S. B. de S. (2019). Estresse e sobrepeso/obesidade em estudantes de enfermagem. Revista Latino-Americana de Enfermagem, 27. https://doi.org/10.1590/1518-8345.2966.3177

Vieira, A. B. D., Alves, E. D., \& Kamada, I. (2007). Cuidando do cuidador : percepções e concepções de auxiliares de enfermagem acerca do cuidado de si. Texto \& Contexto - Enfermagem, 16(1), 17-25.

Vitor, A. F., Lopes, M. V. de O., \& Araujo, T. L. de. (2010). Teoria do déficit de autocuidado: análise da sua importância e aplicabilidade na prática de enfermagem. Escola Anna Nery, 14(3), 611-616. https://doi.org/10.1590/s1414-81452010000300025 